\title{
O CULTO ECÚMENO-CIENTÍFICO: ANÁLISE DO CULTO ECUMÊNICO EM HOMENAGEM AOS DOADORES DE CORPOS
}

\author{
Marcos Freire de Andrade Neves ${ }^{1}$
}

\begin{abstract}
Resumo: Este artigo tem por objetivo fazer uma análise ritual do Culto Ecumênico em Homenagem aos Doadores de Corpos, promovido por uma universidade na cidade de Porto Alegre. Um Culto ecumênico realizado no interior de uma capela universitária, conduzido por profissionais da saúde vestidos com jalecos brancos, e performado por discursos de progresso científico. A partir da descrição, propõem-se questionamentos acerca da noção de sagrado e sua relação com o cadáver humano, bem como concernentes à interação entre religião e ciência.
\end{abstract}

Palavras-chave: Anatomia; Cadáver; Ciência; Ecumenismo; Sagrado.

Abstract: The paper aims to accomplish a ritual analysis of an ecumenical service honoring body donors, promoted by a university in the city of Porto Alegre. An ecumenical service held inside of the university chapel, led by health professionals wearing white coats, and enacted by discourses of scientific progress. Based on the ritual analysis, the paper proposes questions regarding the notion of sacred and its relation to human cadaver, as well as regarding the interaction between religion and science.

Keywords: Anatomy; Cadaver; Science; Ecumenism; Sacred.

1 Mestre em Antropologia Social - PPGAS/UFRGS. Doutorando em Antropologia Social - PPGAS/UFRGS. Contato: marcosfan@gmail.com

Debates do NER, Porto Alegre, Ano i6, N. 27, P. 407-426, JAn./Jun. 2015 


\section{INTRODUÇÃO}

Ao longo de um corredor no térreo da Universidade Federal de Ciências da Saúde de Porto Alegre (UFCSPA), dezenas de conversas ressoavam perdidas em meio aos grupos lá formados. Eram alunos e funcionários, todos vestidos casualmente e situados próximos à entrada do edifício, em um horário no qual as aulas deveriam ter sido há pouco finalizadas. A movimentação, ora casual e descontraída, alterava-se na medida em que eu alcançava a outra ponta do corredor.

Era a Capela da UFCSPA. Lá, e em seu entorno, todos trajavam jalecos brancos com uma discreta costura na altura do peito esquerdo, por meio da qual o nome de cada estudante se tornava público. No seu interior, seis bancos de madeira, similares aos encontrados em igrejas católicas, estavam dispostos em direção ao altar, no qual, de um lado, um púlpito aguardava para ser utilizado e, do outro, alguns estudantes tocavam e cantavam músicas ambientais. Nenhum símbolo religioso integrava o espaço que, não fosse pela estética dos bancos e dos coloridos vitrais, poderia ser uma simples sala de reunião.

Em cerca de vinte minutos, começaria o "Culto Ecumênico em Homenagem aos Doadores de Corpos" (doravante "Culto"), promovido, no final de 2012, pela disciplina de Anatomia da UFCSPA, com o intuito de prestar homenagem "aos doadores de corpos por seu gesto altruísta para com o ensino e formação de futuros profissionais da área de saúde"2. O artigo consiste, portanto, em uma análise ritual delimitada ao espaço - físico e temporal ocupado pelo Culto. Se à primeira vista a ausência de símbolos religiosos no local parecia contrastar com a presença de uma atmosfera repleta de insinuações religiosas, em um aparente, porém discreto, flerte performático entre ciência - responsável pela condução do Culto - e religião, o ritual

2 Conforme cartaz de divulgação do evento. 
sintetizou um modo de associação performatizado ${ }^{3}$ por aspectos de diversas ordens. Práticas e materialidades associadas à religião e à ciência médica que, uma vez associadas, acabaram por criar um ambiente de análise sui generis propício a questionamentos acerca da ideia de sagrado ${ }^{4}$, bem como concernentes à própria interação entre religião e ciência. Questionamentos posicionados enquanto pontos de partida para reflexôes subsequentes que serão, aqui, elaboradas e ampliadas, indicando possíveis caminhos reflexivos sem, com isso, pretender ambicionar uma solução. É o caminho, e não o ponto de chegada, a preocupação primeira.

3 Performance, aqui, no sentido de construção da realidade, com base na proposição de que esta “[...] não precede as práticas banais nas quais interagimos com ela, antes sendo modelada por essas práticas" (Mol, 2008, p. 63).

4 Tomam-se como inspiração inicial as ideias de religião e sagrado conforme trabalhadas por Durkheim.

Debates do NER, Porto Alegre, Ano i6, N. 27, P. 407-426, Jan./Jun. 2015 
Figura 1 - Cartaz de divulgação do Culto ecumênico.

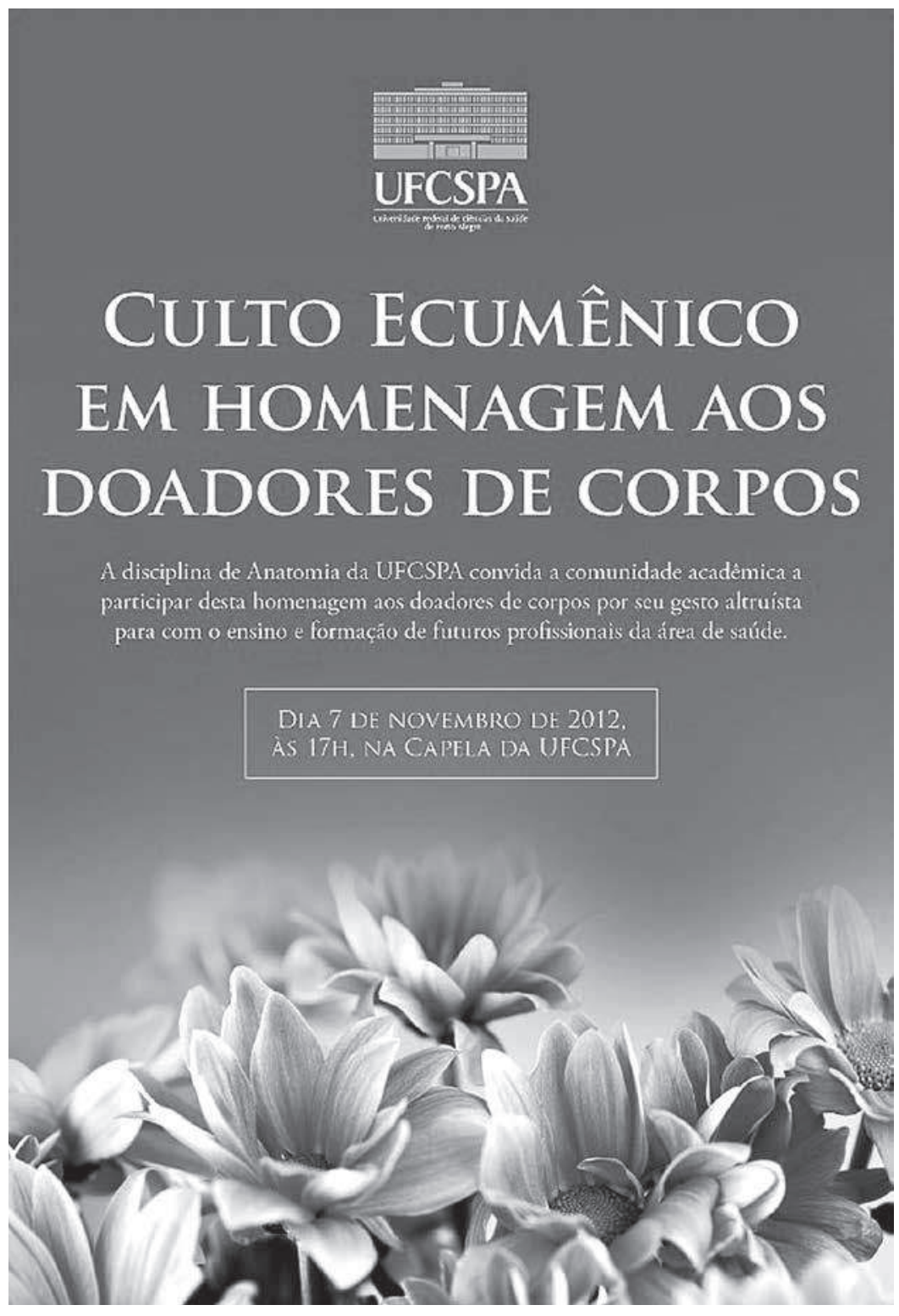

Fonte: Fôlder de divulgação do evento

Debates do NER, Porto Alegre, Ano i6, N. 27, P. 407-426, JAn./Jun. 2015 


\section{O CADÁVER HOMENAGEADO}

Anteriormente ao início do Culto, a impressão de um constante jogo de contrastes. Os alunos e funcionários - todos de jaleco branco no interior da capela - cercavam os seis bancos centrais onde, à exceção de um pequeno espaço na última fileira, sentavam-se familiares dos homenageados na ocasião. Assim como eu, não vestiam branco. As músicas, entoadas pelos estudantes, serviam de preâmbulo à ocasião. Silêncio. Com o cessar das músicas, todos os presentes passaram a ouvir a abertura da cerimônia realizada pela pró-reitora de Graduação da instituição, que, de imediato, passou a palavra à coordenadora do programa de doação de corpos da UFCSPA.

Desde 2008, a Universidade mantém o "Programa de Doação de Corpos para Ensino e Pesquisa”, desenvolvendo uma série de materiais informativos para esclarecer aspectos referentes à doação em vida. Segundo o institucional do programa, "Este [...] fez com que esta instituição pudesse disponibilizar aos seus alunos maior quantidade de material didático de excelente qualidade para o ensino em aulas práticas de anatomia", e conclui:

Assim, ser doador não significa apenas auxiliar neste processo de aprendizagem, mas também representa um ato altruísta que deve levar em consideração o benefício das gerações futuras, as quais irão dispor destes profissionais e dos avanços científicos por eles proporcionados.

A ciência médica, inicia a coordenadora do programa, baseia-se fundamentalmente no ampliado conhecimento da anatomia humana, algo que somente pode ser alcançado a partir do estudo de cadáveres. Em um período de amplas possibilidades técnicas e tecnológicas, a manipulação e o contato com cadáveres se fazem essenciais não apenas como um modo privilegiado de estudo anatômico, mas também, e fundamentalmente, em

5 Disponível em: <http://www.ufcspa.edu.br/index.php/programa-de-doacao-de-corpos>. Acesso em: jul. 2014.

Debates do NER, Porto Alegre, Ano i6, N. 27, P. 407-426, JAN./Jun. 2015 
decorrência do "contato moral" entre o estudante e o corpo morto, colocando o primeiro em uma situação limite na qual é possível perceber a fragilidade da sua condição.

Ainda segundo a coordenadora, o programa de doação voluntária em vida de corpos é responsável pelo progressivo aumento do número de doações que a UFCSPA vem registrando. Consequentemente, e "felizmente", conforme qualifica, tem sido utilizado cada vez menos cadáveres não reclamados, em destacado contraste com práticas de um passado nem tão longínquo assim. Hoje em dia, diz ela, chama-se de não identificado não mais aquele cadáver não reclamado pela família após o óbito, mas sim os doados em vida, cujo anonimato é mantido em virtude de uma responsabilidade ética. Os cadáveres são professores fundamentais na trajetória de formação de profissionais em áreas da saúde, profissionais que, de acordo com o que destacou a oradora seguinte, uma aluna que falou em nome dos seus pares, buscam ser cientificamente competentes e socialmente éticos.

Dois argumentos devem ser destacados dos discursos iniciais proferidos no Culto: a importância do "contato moral" entre o estudante - futuro profissional da saúde - e o cadáver; e a possibilidade de o corpo instruir, o cadáver-professor. Segundo Foucault, foi a partir do séc. XVIII que laboratórios de anatomia passaram a contar com a presença de cadáveres humanos em seus espaços. Passar a utilizá-los representou não somente a ampliação de possibilidades analíticas e um melhor mapeamento da fisionomia humana, mas, fundamentalmente, permitiu identificar o corpo enquanto um locus discursivo objeto de reflexão científica (1994, p. XIII). O corpo instrui e influencia.

O interesse científico na utilização de cadáveres humanos - tal qual defendido pela coordenadora do "Programa de Doação de Corpos para Ensino e Pesquisa" em sua fala - pôde ser apreendido já no século XVIII, através da promulgação do chamado decreto de Marly, que, conforme transcreveu Foucault, ordena "[...] aos magistrados e diretores dos hospitais que forneçam cadáveres aos professores para as demonstrações de anatomia e o ensino das operações cirúrgicas" (1994, p. 142-143). O intuito científico 
sugerido pela redação do decreto de Marly - que, de modo geral, embasou o início da utilização de cadáveres humanos como objetos de reflexão também envolveu, em sua trajetória, objetivos religiosos. No final do séc. XIX até a metade do séc. XX, na França, esteve ativa a chamada "Sociedade de Autópsia Mútua" [Société d'autopsie mutuelle], fundada por antropólogos e, posteriormente, atraindo centenas de novos membros que compartilhavam duas características centrais: ateísmo e curiosidade científica. Segundo Hecht,

Enquanto todos os fundadores e membros descreveram seus esforços como profundamente seculares, as autópsias e rituais auxiliares da sociedade foram modelados em comportamentos religiosos. De fato, os fundadores criaram um sistema memorial litúrgico e confessional, e, de maneira surpreendentemente autoconsciente, os membros abraçaram esse sistema devocional como uma substituição a um desdenhado Catolicismo (2003, p. 6-7, tradução nossa).

Os membros dessa Sociedade tinham por objetivo confirmar, por meio da dissecação de cérebros, a inexistência da alma. Em outras palavras, procuravam meios científicos de confirmar seus posicionamentos religiosos ao assegurar que a alma era, de fato, explicável anatomicamente. No entanto, conforme argumenta Hecht, tal interação entre religião e ciência acabou por fazê-los incorporar uma liturgia ritual quasi religiosa. Dessa forma, percebe-se que a incorporação de corpos humanos no cotidiano de laboratórios de anatomia, embora mediante o argumento em prol da ampliação das possibilidades de reflexão científica - segundo observado na redação do decreto de Marly, no século XVIII, e ainda hoje, no Art. 14 da Lei 010.406.2002 do Código Civil Brasileiro: “[...] é válida, com objetivo científico, ou altruístico, a disposição gratuita do próprio corpo, no todo ou em parte para depois da morte." -, acabou por incorporar, em sua trajetória histórica, praticalidades próximas da religião.

No Culto, conquanto tenham sido afirmados pelos oradores os avanços científicos e médicos que a manipulação de cadáveres tenha impulsionado, outra dimensão é posta em consideração pela coordenadora do "Programa de Doação de Corpos para Ensino e Pesquisa”, em cujo discurso abordou

Debates do NER, Porto Alegre, Ano i6, N. 27, P. 407-426, JAn./Jun. 2015 
a importância do "contato moral" entre o estudante e o cadáver. Segundo ela, a dimensão moral, e não apenas a relevância técnica, agrega a argumentação a favor da premência do uso de cadáveres nos laboratórios, pois para além dos significativos avanços que tal prática tenha representado, torna-se imprescindível colocar, frente a frente, o corpo morto e o profissional da saúde - porquanto este também é o profissional da morte (Menezes, 2004). A dimensão moral - tal qual proposta pela coordenadora do Programa pode ser observada em concomitância com a dualidade sagrado/profano postulada por Durkheim, conforme a qual o indivíduo construído socialmente, o indivíduo abstrato, pertence ao domínio do sagrado enquanto, por seu turno, ao indivíduo identificável, individual, reserva-se o profano (Pickering, 2009, p. 120). Desse modo, o corpo individual seria profano frente à sacralidade do indivíduo ideal, abstrato. A escolha pela realização de um Culto ecumênico, dentre outras formas possíveis de homenagem àqueles que efetuaram a doação de seu corpo, possibilita ponderar o local do corpo doado em meio a esta dualidade.

Após a primeira definição do sagrado no Lectures on the religion of the Semites, escrito por Robertson Smith no final do século XIX, muito foi a ele incorporado. Em seu texto, Smith escreve:

Junto a tabus que correspondem exatamente a regras de santidade e que protegem a inviolabilidade dos ídolos, dos santuários, dos sacerdotes, dos chefes e, em geral, das pessoas e das coisas que pertencem aos deuses e ao seu culto, encontramos uma outra espécie de tabu que, em um âmbito semítico, tem seu paralelo nas regras de impuridade. As mulheres após o parto, o homem que tocou um cadáver etc., são temporariamente tabus e são separados do consórcio humano (Smith, 1894, p. 152-153 apud Agamben, 2002, p. 78)

Por conseguinte, as noções de sagrado e tabu pareciam seguir caminhos paralelos identificáveis, posteriormente, na ideia durkheimiana de sagrado baseada no fato de sociedades cultivarem objetos, pessoas e ideias enquanto possuidores de um caráter inviolável (Pickering, 2009, p. 115). No texto de Smith, a menção ao tabu referente ao ato de tocar um cadáver indica algo 
nefasto que acarreta, do modo invariável, um status de impureza sobre o praticante de tal ação. O cadáver impuro.

Assim como Smith, Rodrigues relata algo similar ao discorrer sobre os tabus relacionados ao corpo:

O certo é que o morto, como as coisas insólitas, anormais ou ambíguas, constitui um ser impuro cujo contato representa perigo para o mundo das normas. Em muitas sociedades ameaça manchar a todos e a tudo que tem ou teve contato com ele - incluindo seus pertences -, já que tudo que se relaciona com um morto participa de sua perigosa personalidade: se ele é tabu, são também tabu suas propriedades [...]. (Rodrigues, 2006a, p. 52)

Se por um lado a violação de tabus incorre em ato nefasto, pelo outro os tabus não são inalteráveis. Eles estão sujeitos a mudanças, seja internamente a um grupo ou entre grupos distintos, alterando, por consequência, o que é e deixa de ser consagrado ${ }^{6}$. Os conceitos permanecem em movimento, deslocando-se em meio a compreensões e significados distintos na medida em que são utilizados:

$\mathrm{Na}$ vida dos conceitos, há um momento em que eles perdem a sua inteligibilidade imediata e, como todo termo vazio, podem carregar-se de sentidos contraditórios. [...] Considerações de certo modo análogas poderiam ser feitas sobre os conceitos de tabu e de sacro, alusivas ao seu uso e à sua função no discurso das ciências humanas entre 1890 e 1940 (Agamben, 2002, p. 82).

As constantes mudanças na posição social ocupada pela morte nas sociedades ocidentais, tema sobre o qual se debruçam diversos trabalhos (dentre eles: Ariès, 1981; 2003; Elias, 2001; Rodrigues, 2006b; Menezes, 2004), sugere - à primeira vista - o deslocamento de um maior contato e uma verbalização da morte para um silenciamento rigoroso e, com frequência, um obscurecimento por metáforas (Rodrigues, 2006a, p. 52). Em referência

6 Etimologicamente, em sua derivação latina, o termo sacer denota não apenas "santo" e “consagrado", mas também "amaldiçoado" e "horrível” (Pickering, 2009, p. 124).

Debates do NER, Porto Alegre, Ano i6, N. 27, P. 407-426, Jan./Jun. 2015 
a esse movimento, Gorer estabelece uma relação entre a progressiva exclusão da morte como tema a partir do século XX - seu crescente encobrimento na vida social - e, em sentido oposto, a maior publicização da obscenidade, no que seria, segundo o autor, uma inversão de tabus:

No Séc. XX, entretanto, parece ter havido uma notável alteração no pudor; enquanto copulação se tornou mais e mais 'mencionável', particularmente em sociedades Anglo-saxãs, a morte se tornou mais e mais 'não mencionável' enquanto um processo natural. [...] Parece possível traçar uma conexão entre a mudança de tabus e a mudança nas crenças religiosas (1955, p. 50-51, tradução nossa, grifo do autor).

As mudanças nas crenças religiosas, argumenta o autor, relacionam-se a questôes de vida após a morte e pecaminosidade do corpo (1955, p. 51). Embora o argumento de Gorer em prol de um movimento histórico de ocultação e visibilidade social da morte pode ser contraposto com o questionamento acerca da própria estabilidade da morte enquanto fenômeno - isto é, deve-se ponderar a própria noção de morte enquanto fenômeno natural estável e reconhecê-la em termos de processo social e político, sujeito a critérios de época e disciplinares (Agamben, 2010; 2006; Andrade Neves, 2014; Lock, 2002; 1996; Macedo, 2012) -, sua análise indica o caráter mutável dos tabus e, por extensão, daquilo que se consagra ou deixa de consagrar.

O sagrado pode ser entendido enquanto um sentimento, uma percepção da vida coletiva: é sagrado aquilo que a sociedade consagra. Desse modo, parece haver uma dimensão mais imediata, mais sensível, que instaura uma sacralidade ao cadáver humano. Não se deve profaná-lo. A constante preocupação ética e o respeito com que se procura, idealmente, manipulá-lo, impõem constrangimentos e amarras responsáveis, em grande medida, pelo efeito que o contato com o cadáver causa. ${ }^{7}$ Se, para Rodrigues, "Ninguém

7 Vale notar, contudo, que o postulado durkheimiano entende a alma enquanto sagrado, em oposição ao caráter destinado ao corpo humano. Conquanto a homenagem possa

Debates do NER, Porto Alegre, ANo i6, N. 27, P. 407-426, JAN./Jun. 2015 
permanece perto de um cadáver sem que sua fisionomia ateste que é precisamente um cadáver o que está vendo" (2006a, p. 52), é justamente esse desconforto a base do "contato moral" mencionado durante o Culto.

Em um contexto de novas tecnologias que visam à substituição de corpos humanos por materiais sintéticos para o estudo anatômico, recorrer ao contato moral é, simultaneamente, um modo de reafirmar a importância de sua presença no ambiente acadêmico médico e de estabelecer um posicionamento político em seu favor. O cadáver-professor enquanto um objeto de sacralização e, por conseguinte, passível de ser homenageado mediante a realização de Culto ecumênico. Contudo, enquanto um ritual performado através de praticalidades e discursos associados à religião e às ciências da saúde, a homenagem sugere formas locais de experienciar o sagrado e o secular.

Bellah, ao discorrer sobre a separação entre Estado e igreja nos Estados Unidos, argumenta que esta cisão não significou a negação de uma dimensão religiosa ao espaço do político. Estado e religião, diz o autor, estão relacionados através de uma religião civil, isto é, "um conjunto de crenças, símbolos e rituais" que se fazem presente no cotidiano social e permanecem, inclusive, no mundo político (1991, s/p). A proposta do autor fornece elementos para pensar o local do secular no Culto, o qual transcorreu no interior de um edifício público federal. Se o processo de secularização distanciou o religioso transformando-o em uma dentre diversas possibilidades e visões de mundo (Dullo, 2012), no ambiente do Culto, percebe-se um espaço de tensionamento entre secularismo e religião, porquanto o ambiente institucional laico abriga uma capela, sem símbolos religiosos, onde uma celebração proposta por profissionais das ciências da saúde congrega aspectos associados à religião.

ser destinada à alma dos doadores - ou às suas memórias -, a não profanação dos corpos mortos e o trato a eles destinados indicam um impedimento moral relacionado a determinadas atitudes. Indicam, em suma, uma certa sacralidade.

Debates do NER, Porto Alegre, Ano i6, N. 27, P. 407-426, JAn./Jun. 2015 


\section{ASSOCIAÇÕES E SÍNTESE}

Dentre todos os oradores do Culto, a única menção direta à religião ficou sob responsabilidade da dirigente do departamento doutrinário da Federação Espírita do Rio Grande do Sul. Em sua fala, contou a alegoria de uma mãe que perde o filho em decorrência de câncer: após morrer e ascender aos céus, o filho encontrou Jesus - "apesar de reconhecê-lo instantaneamente, não era similar aos retratos que costumamos observar", disse a dirigente e, com sua autorização e caneta pessoal, escreveu uma carta para consolar a mãe. Conforme já havia expressado em vida, a criança gostaria que seu corpo ficasse a cargo dos médicos para que o seu estudo possa, futuramente, "permitir que outros filhos fiquem mais tempo perto de suas mães".

Findo os discursos, outra homenagem. Dez velas, empunhadas por alunos, foram trazidas do segundo andar em direção ao altar da capela, seis delas em homenagem aos cadáveres doados naquele ano e as quatro restantes aos cadáveres doados em anos anteriores. Ao som de Amazing Grace e Gostava tanto de você, um por um, os estudantes posicionaram-se ao longo de duas fileiras sobre o altar. Quando a música cessou, seguiram o caminho oposto, um a um, apagando sua vela e retornando ao andar superior. Em seguida, dois alunos carregando caixas repletas de rosas brancas e pequenas velas distribuíram o conteúdo entre todos os familiares presentes.

A simbologia subjacente à escolha por realizar um Culto ecumênico, em uma capela universitária, com distribuição de flores e velas, contrasta sobremaneira com a ausência de símbolos e menções religiosas explícitas em um procedimento conduzido por (futuros) profissionais da saúde em seus brancos jalecos - um ritual ecumênico performado por discursos de progresso científico. Em um primeiro momento, parece haver a identificação de uma assinatura ritual religiosa preenchida por discursos relacionados a uma agenda científica. Sob esta primeira perspectiva, poder-se-ia argumentar superficialmente em prol da incorporação da ideia de sagrado pela ciência, em um modelo de sagrado metaforizado. 
A possibilidade de o sagrado ser pensado metaforicamente, enquanto base de uma relação ou articulação distante da religião, sugere o entendimento do Culto enquanto um modo de apropriação da ideia de sagrado pelas ciências da saúde. Escolher um procedimento ritual, uma localização e um nome próximos à religião, porém preenchê-lo com discursos de outra ordem, constituiria um deslocamento da noção com o intuito de criar uma identificação entre a homenagem proposta e os familiares dos homenageados. Uma situação na qual a ciência médica se apropria de moldes religiosos e da noção de sagrado através de uma performatização ritual - afinal, segundo Pickering, o ritual pode ser compreendido enquanto o "[...] elemento -ação da religião que se preocupa com as coisas sagradas” (2009, p. 117, tradução nossa); uma relação facilmente percebida, porém não diretamente verbalizada. Um segredo compartilhado (Taussig, 1999) entre todos os envolvidos, sejam organizadores ou espectadores. A partir de tais proposições, o Culto ecumênico atuaria com uma assinatura religiosa responsável pela aparência do ritual enquanto seu conteúdo transitaria em uma retórica de progresso científico.

Conquanto constitua um caminho argumentativo, explicar o Culto a partir de uma fundamentação na ideia de metáfora comporta, em si mesmo, certa arrogância epistemológica por instituir ao conceito um significado central e outros, periféricos, a ele vinculados. A metáfora implica uma dinâmica de empréstimos de significados entre um domínio abstrato e outro concreto, sob uma lógica composta por essência e derivaçóes. Derivações que tomam de empréstimo significados com o intuito de "[...] apresentar uma ideia sob o signo de outra ideia mais impressionante ou conhecida" (Ricoeur, 1983, p. 94). A ciência médica, provida de seu próprio sistema classificatório e, por conseguinte, de seus próprios objetos de sacralização, define a sua relação puro/impuro conferindo certa proximidade - e continuidade - à lógica dos rituais religiosos. No Culto, não se trata de empréstimo de significados, mas sim de pensar as formas de associação entre religião e ciência.

Debates do NER, Porto Alegre, Ano i6, N. 27, P. 407-426, JAn./Jun. 2015 
Quando Aron debate As Formas Elementares da Vida Religiosa, o faz contextualizando sua elaboração em meio a um momento no qual a ciência, de maneira similar à atualidade, é vista enquanto detentora da "autoridade intelectual e suprema" (2003, p. 498). O trabalho de Durkheim foi, nesse sentido, um modo de sugerir uma solução aos espaços ocupados pela ciência e pela religião. Dessa forma, escreve Aron:

Descobrindo a realidade profunda de todas as religióes, a ciência não recria uma religião, mas dá confiança na capacidade que têm as sociedades de produzir em cada época os deuses de que necessitam: 'Os interesses religiosos não passam da forma simbólica de interesses sociais e morais' (2003, p. 498).

A relação entre ciência e religião, tal qual exposta por Aron, possui paralelos com a argumentação de Asad:

[...] meu argumento aqui é que o saber opcional exprimido pelo termo perspectiva é certamente enganador quando aplicado igualmente à ciência e à religião na sociedade moderna: a religião é, de fato, hoje, opcional de um modo que a ciência não é. Práticas científicas, técnicas, conhecimentos, permeiam e criam as fibras da vida social de um modo que a religião não mais pode igualar (2010, p. 275, grifo do autor).

Embora as duas argumentações convirjam na percepção acerca dos locais ocupados pela religião e pela ciência no cotidiano social - destacando, em ambos os casos, a centralidade da ciência em que, outrora, figurava a religião -, Asad vai além ao argumentar sobre a impossibilidade de alcançar uma definição universal de religião. "Não apenas porque seus elementos constituintes e suas relações são historicamente específicos", escreve o autor, "[...] mas porque esta definição é ela mesma o produto histórico de processos discursivos" (2010, p. 264). Em outras palavras, trata-se de não buscar uma essência ao conceito de religião, e sim associá-lo sempre a um processo histórico situacional. 
Pensar a partir do resultado da interação entre ciência e religião acaba, como consequência, por cristalizar dois campos da vida social. A impossibilidade de esboçar uma definição de religião alheia a contextos e situações específicas, conforme argumentou Asad, indica, precisamente, a premência de resistir ao impulso cristalizador, isto é, de encerrar determinadas características no interior de fronteiras rígidas de definição. Fronteiras que não se desfazem e permitem apenas o intercâmbio de suas características constitutivas. No Culto, não há como definir momentos "essencialmente" religiosos ou científicos, conquanto seja possível associar determinadas praticalidades a um dos dois campos. Nele, há tanto uma forma de pensar e experienciar o religioso através de discursos científicos quanto de vivenciar o científico através de uma lógica religiosa. Não é possível dissociar as práticas, conforme demonstra a comunicação da dirigente do departamento doutrinário da Federação Espírita do Rio Grande do Sul: uma agente religiosa, em um Culto ecumênico, proferindo um discurso que associa a experiência da criança ao encontrar Jesus à sua vontade de auxiliar a medicina em pesquisas por meio da doação de seu corpo. Outra demonstração é a "Oração ao cadáver desconhecido", escrita, em 1876, por Carl Von Rokitansky, e lida no Culto:

Ao curvar-te com a lâmina rija de teu bisturi sobre o cadáver desconhecido, lembra-te que este corpo nasceu do amor de duas almas; cresceu embalado pela fé e esperança daquela que em seu seio o agasalhou, sorriu e sonhou os mesmos sonhos das crianças e dos jovens; por certo amou e foi amado e sentiu saudades dos outros que partiram, acalentou um amanhã feliz e agora jaz na fria lousa, sem que por ele tivesse derramado uma lágrima sequer, sem que tivesse uma só prece. Seu nome só Deus o sabe; mas o destino inexorável deu-lhe o poder e a grandeza de servir a humanidade que por ele passou indiferente.

Têm-se, portanto, uma oração que não remete à transcendência em um Culto ecumênico sem qualquer demonstração inter-religiosa. No entanto, a despeito de qualquer significação formal dos termos, o encontro

Debates do NER, Porto Alegre, Ano i6, N. 27, P. 407-426, JAn./Jun. 2015 
manteve-se enquanto um Culto ecumênico na medida em que seus integrantes o pensavam, vivenciavam e, em última medida, o performavam enquanto tal.

Retornando à Sociedade de Autópsia Mútua, o esforço científico em virtude de um posicionamento religioso culminou em uma síntese entre os dois campos:

Os antropólogos que criaram a Sociedade de Autópsia Mútua eram autoproclamados ateus - livres pensadores - que explicitamente desejavam que a ciência pudesse substituir a religião. Ao fundar a sociedade, os antropólogos livres-pensadores estavam construindo uma arena para proclamaçôes e celebrações ateias, criando rituais ativos e cientificamente orientados para uma comunidade que de outra maneira era unida apenas pela rejeição de metafísicas e pela recusa de tomar parte em cerimônias da fé (Hecht, 2003, p. 7, tradução nossa).

Não se trata, no âmbito da atuação dessa Sociedade específica, de uma forma metaforizada de religião ou sagrado. O que está em jogo é a constituição de um conjunto de praticalidades que sintetizam aspectos associados à religião e à ciência. Embora tenham desenvolvido uma liturgia que poderia, ao primeiro olhar, ser associada à religião, dificilmente eles a descreveriam - e se reconheceriam - enquanto inscrita neste campo.

No "Culto Ecumênico em Homenagem aos Doadores de Corpos", percebe-se um conjunto de aspectos com características que seriam - com facilidade - associadas às ideias de religião e ciência. Uma capela; velas; flores; jalecos brancos; orações; condução ritual por um estudante de ciências médicas. Antes de uma relação entre aparência e essência (Taussig, 1999), há a construção de um ritual específico por meio de praticalidades, discursos e objetos que não são nem puramente e apenas religiosos nem puramente e apenas científicos, porquanto, se o fossem, cairíamos novamente em uma lógica cristalizante.

Parece haver, em suma, um jogo de interessamentos (Callon; Law, 1998) através do qual os diferentes atores envolvidos no Culto supóem engajar os outros. A escolha por um Culto ecumênico pode ter sido intencionada a 
estabelecer uma associação entre os parentes dos homenageados e a instituição de ensino por meio de um modelo consolidado de homenagem; discursos voltados ao progresso da ciência, inclusive os proferidos com associaçôes a aspectos relacionados à religiáo: pode ter sido uma forma de atrair e angariar novos doadores. É o reconhecimento, escreve Kleinman, "[...] de que algo está em jogo para todos nós envolvidos na rotina diária de acontecimentos e transaçôes" (1995, p. 277, grifo do autor).

\section{CONSIDERAÇŌES FINAIS}

O "Culto Ecumênico em Homenagem aos Doadores de Corpos" foi um disparador de questionamentos acerca do local do cadáver humano na dualidade sagrado-profano, lançando mão de exemplos que mostram o deslocamento de tabus relacionados à morte e, concomitantemente, o constante processo de atualização sofrido pelos conceitos. Sobretudo, foi uma possibilidade ritual de pensar os modos de associação entre ciência e religião. Associações que derivam de práticas e discursos que, embora associemos a um destes campos da vida social, não lhes são exclusivos.

As praticalidades conformam um conjunto de aspectos e características passíveis de vinculação religiosa ou científica, mas cuja síntese - nesse caso, o Culto - extrapola os limites de tais definições. Não há uma circunscrição responsável pela cristalização de um campo cuja essência deve ser preservada, mas uma série de práticas que constroem a realidade através da interação.

Se, historicamente, podemos identificar na Sociedade de Autópsia Mútua uma modalidade de síntese, de construção da realidade, através do desenvolvimento de um ateísmo-litúrgico-científico, o Culto foi construído de modo a comportar um modelo ritual ecúmeno-científico. Um modelo em que orações não remetem à transcendência e ecumenismo não indica inter-religiosidade, embora oração e ecumênico permaneçam vistos como tais. Um modelo em que cientistas sobem ao púlpito de uma capela com a atribuição de conduzir um Culto ecumênico. Um modelo que, em suma, não é necessariamente religioso nem científico, mas uma síntese que não deixa de sê-los.

Debates do NER, Porto Alegre, Ano i6, N. 27, P. 407-426, JAn./Jun. 2015 


\section{REFERÊNCIAS}

AGAMBEN, Giorgio. Homo Sacer: o poder soberano e a vida nua I. Belo Horizonte: Editora UFMG, 2010.

A linguagem e a morte: um seminário sobre o lugar da negatividade. Belo Horizonte: Editora UFMG, 2006.

ANDRADE NEVES, Marcos. Por onde vivem os mortos: o processo de fabricação da morte e da pessoa morta no segmento funerário de Porto Alegre. 2014. Dissertação (Mestrado em Antropologia Social)-PPGAS/ UFRGS, Porto Alegre, 1997.

ARIÈS, Phillipe. O homem diante da morte. Rio de Janeiro: Francisco Alves, 1981.

História da morte no Ocidente. Rio de Janeiro: Ediouro, 2003.

ARON, Raymond. As etapas do pensamento sociológico. São Paulo: Martins Fontes, 2003.

ASAD, Talal. A construção da religião como uma categoria antropológica. Cadernos de Campo, São Paulo, n. 19, 2010.

BELLAH, Robert. Beyond Belief: Essays on Religion in a Post-Traditionalist World. Berkeley: University of California Press, 1991.

BRASIL. Código Civil Brasileiro. Lei no 10.406, de 10/01/2002.

CALLON, Michel; LAW, John. De los intereses y su transformación. Enrolamiento y contraenrolamiento. In: DOMĖNECH, Miquel; TIRADO, Francisco Javier (Org.). Sociología simétrica: ensayos sobre ciencia, tecnologia y sociedad. Barcelona: Gedisa, 1998.

DULLO, Eduardo. Após a (Antropologia/Sociologia da) Religião, o Secularismo? Mana, Rio de Janeiro, v. 18, n. 2, 2012. 
ELIAS, Norbert. A Solidão dos Moribundos. Rio de Janeiro: Jorge Zahar Ed., 2001.

FOUCAULT, Michel. O nascimento da clínica. Rio de Janeiro: Forense Universitária, 1994.

GORER, Geoffrey. The Pornography of Death. Encounter. Disponível em <http://www.unz.org/Pub/Encounter-1955oct-00049>. Acesso em: 19 maio 2015.

HECHT, Jenniffer. The end of the soul: scientific modernity, atheism, and anthropology in France. Nova York: Columbia University Press, 2003.

KLEINMAN, Arthur. Suffering and its Professional Transformation: toward and Ethnography of Interpersonal Experience. In: KLEINMAN, Arthur. Writing at the Margin. Berkeley, University of California Press, 1995.

LOCK, Margaret. Twice dead: organ transplants and the reinvention of death. Berkeley; Los Angeles: University of California Press, 2002.

Death in Technological Time: Locating the End of Meaningful Life. Medical Anthropology Quarterly, v. 10, n, p. 575-600, 1996.

MACEDO, Juliana Lopes de. Quando a vida encontra a morte: as concepções médicas e jurídicas sobre anencefalia e morte encefálica. Porto Alegre: UFRGS/PPGAS, 2012.

MENEZES, Rachel Aisengart. Em busca da boa morte: antropologia dos cuidados paliativos. Rio de Janeiro: Garamond; FIOCRUZ, 2004.

MOL, Annemarie. Política Ontológica: algumas ideias e várias perguntas. In: NUNES, João Arriscado; ROQUE, Ricardo (Org.). Objectos Impuros. Experiências em estudos sociais da ciência. Porto: Edições Afrontamento, 2008.

PICKERING, William. Durkheim's Sociology of Religion: Themes and Theories. Cambridge: James \& Clarke, 2009. 
RICOEUR, Paul. A Metáfora Viva. Lisboa: Res, 1983.

RODRIGUES, José Carlos. Tabu do corpo. Rio de Janeiro: Editora Fiocruz, 2006 .

Tabu da Morte. Rio de Janeiro: Editora Fiocruz, 2006b.

TAUSSIG, Michael. Defacement. Stanford: Stanford University Press, 1999. Transgression. In: TAYLOR, Mark (Ed.). Critical Terms for Religious Studies. Chicago: The University of Chicago Press, 1997.

Recebido em: 31/07/2014

Aprovado em: 09/08/2014 